\title{
Metro station inauguration, housing prices, and transportation accessibility: Tehran case study
}

\author{
Yekta Yazdanifard \\ Hosein Joshaghani \\ Sharif University of Technology \\ Khatam University \\ Masoud Talebian \\ Sharif University of Technology
}

\begin{abstract}
The opening of a new metro station, as a mode of the transportation corridor, potentially could have different effects on housing prices. We have investigated its effect on the value of residential properties around those stations, using data from large expansions of the metro network in Tehran, Iran. In the period of our study (April 2010 to December 2018), forty-five metro stations were inaugurated in Tehran. We use a difference-in-difference regression method to identify the causal effect of interest, where adjacent properties are used as the treatment group and similar but distant properties as the control group. The results indicate that, on average, the adjacent properties are affected by a 3.7 percent increase in price relative to distant properties. We also extend our study by categorizing new metro stations according to the extent of ex-ante access to other modes of public transportation such as bus rapid transit (BRT). We find 2 to 11 percent positive effect of new metro stations in regions with lower public transport, while in regions with ex-ante extensive public transportation system, we find less than 2 percent positive effect.
\end{abstract}

Article History:

Received: June 5, 2019

Accepted: May 27,

2020

Available online: April

26,2021

\section{Introduction}

Public transportation in large cities and metropolitan regions is of paramount importance, and therefore are policies regarding its creation and expansion. While the transportation corridors can bring some disadvantages to residents adjacent to them, e.g., crowding and pollution, they are mainly perceived as advantageous because they make the region more accessible and easier for daily commutes. Therefore, it is expected that nearby housing prices to increase due to more and faster access to other regions of the city. In this study, we not only measure this effect but also examine factors that determine its magnitude.

Our unique administrative data comes from Tehran, and we consider the total number of 1,336,266 transactions. Tehran is the capital and biggest city of Iran and home to about 10 million population.

Copyright 2021 Yekta Yazdanifard, Hosein Joshaghani, Masoud Talebian.

doi: $10.5198 /$ jtlu.2021.1622

ISSN: 1938-7849| Licensed under the Creative Commons Attribution - NonCommercial License 4.0.

The Journal of Transport and Land Use is the official journal of the World Society for Transport and Land Use (WSTLUR) and is published and sponsored by the University of Minnesota Center for Transportation Studies. 
Tehran is quite a heterogeneous city regarding income and wealth, and housing prices range from less than $\$ 300$ to $\$ 10,000$ per square meters.

The first metro line in Tehran was launched at 1999, and it currently includes 5 operational lines and 105 stations, 20 of which are interchange stations. As noted by Railway-Technology.com (2014), Tehran Metro currently ranks fifth in Asia and is planned to have 9 lines once all construction is completed by 2020. It is mostly underground, runs from 5:30 to 23:00 all weekdays, and transports about 2.5 million passengers daily. The total length of the metro is $120 \mathrm{~km}$, where the longest one is Line 1 with a length of 28 kilometers.

It is worth mentioning that the housing prices have not only been affected by metro stations but by many other factors. To overcome this difficulty, we use difference-in-difference method by building treatment and control groups. As known, the difference-in-differences methodology can identify the causal effect of the new metro service, as opposed to describing simply correlations.

We use parametric estimation methods, using station proximity as a distance category measure. We treat neighborhood characteristics as a single dummy variable, similar to Bajic (1983) and many other papers. We apply Euclidean distance and use 400 meters as a threshold as it indicates a walking distance neighborhood (Hu et al. (2019)), about 5-minute walking distance ${ }^{1}$.

The location of metro station is important because of income rate of households living around, as well as the extent and quality of public transportation available in the region varies geographically. Richness of our administrative data, and our identification strategy, make it possible to investigate the effect of bus and train as substitute modes of public transportation. We examine whether and to what extent the effect of metro stations is different in comparison to already existing rapid buses relative to regions with less access to public transport. Also, it can help us to understand if the increase in prices close to metro station is due to a better transportation or there are other factors affecting it. To investigate the issue, we categorize stations based on whether there already exist public transportation or not.

Urban policies create externalities which are usually hard to measure, and we believe our study can shed some light on policy evaluation based on evidence. More specifically, the change in market prices for properties with good access to stations can be a proxy for the value of metro. While metro fares have been constant, the costs have increased, and the government and municipal funds are not enough to support it; this situation is not limited to Iran, Diao (2015) reports that government subsidies reached US $\$ 35.4$ billion in 2006 in the United States.

Rest of the paper is as follows. Related literature is reviewed in chapter 2. All data used in this paper is thoroughly introduced in chapter 3. For interested readers, more sophisticated detail about our data is presented in appendix A of the paper. In chapter 4 we present our methodology to control for the confounding factors. Then, in chapter 5 we present our results and chapter 6 concludes.

\section{Literature Review}

Transportation can affect the form of cities and their built environment, we refer to Badoe and Miller (2000) for a survey. There exists a vast scientific literature about the factors affecting housing prices, applying quantitative and qualitative methods. This effect is one of the key aspects examined in the creation of transport passages, in particular railways and stations, in cities. Transport passages affect housing prices through two main factors: 1) easier access which is positive and 2) disturbance, noise, crime rates, and pollution which is negative. The after-mentioned studies focus on these two effects, estimating which effect is dominant.

There are two early reviews of the empirical research about land property values and transportation facilities. Vessali (1996) finds that the impact of rapid transit on property value is about 6-7\%. Ryan

\footnotetext{
${ }^{1}$ In the online appendix, for robustness check, we investigate 300, 400, 500 and 600 meters as the threshold. Results remains both qualitatively and quantitatively the same.
} 
(1999) discusses the existing inconsistency in results about how transport is connected to land-use and housing prices, which may be due to the complexity of metropolitan development and unpredictable travel patterns.

Most studies indicate that a shorter distance from houses to metro stations will lead to an increase in the prices. Chen et al. (1998) study Portland and show that property value decreased at the rate of $\$ 32.30$ per meter away from the station. It implies that the positive effect dominates the negative effect, which implies a declining price gradient as one moves away from light rail train (LRT) stations for several hundred meters. Murat Celik and Yankaya (2006) found that the proximity to rail stations in Izmir, Turkey was valued at $\$ 250-300$ per meters, and the value of per hour closer to the station was $\$ 1.47-1.83$ on average in every travel. Hess and Almeida (2007) estimated that in the study region in Buffalo New York, every foot closer to a light rail station increases average property values by $\$ 2.31$. Consequently, a home located within one-quarter of a mile radius of a LRT station can earn a premium of $\$ 1300-3000$, or $2-5$ per cent of the city's median home value.

Some other papers denote that the effect of new metro stations on residential property value is generally positive. Bajic (1983) studied the new Spandina subway development in Toronto and found a positive effect which can be attributed to the time taken by public transport from the property to the downtown. He concluded that the direct savings in commuting costs have been capitalized into housing values. McMillen and McDonald (2004) examined the effect of the new rapid transit line from downtown Chicago to Midway Airport on single-family house prices before and after the opening of the line. The difference between the increases in the value of houses within the sample region as compared with houses farther away from the new transit stations was approximately $\$ 216$ million between 1986 and 1999. Coffman and Gregson (1998) also checked out the same test in the Knox County, Illinois and the result was the land in close proximity to new railroads became more valuable because of decreased transportation costs. Diao et al. (2017) examined the effects of metro station construction on residential property prices in Singapore. In this important paper, unlike other articles, the network distance was used instead of Euclidean distance. Because the presence of rivers and highways in the city of Singapore, network distance of two points may be quite different compared to their Euclidean distance. The result of the model used on the Singapore data indicates that homes located less than 600 meters in the metro station experienced a price increase of $8.6 \%$ compared to other homes. Wu et al. (2015) uses a spatial multi-intervention difference-in-difference method to investigate the opening and planning impacts of transport improvements on land markets. The result in a mega-city of China shows that residential and commercial land parcels receiving increased station proximity have experienced appreciable price premiums. Chica-Olmo et al. (2019) applied hedonic regression to study the effect of proximity to freight trains on real state. The results of Debrezion et al. (2011) from studying cities in Netherlands also support that proximity to train stations increases the property value, although they report some negative effects of train proximity due to noise nuisance.

More recent papers show that public transport is characterized as less important for higher price segments, or segments with already good access to public transportation. Bohman and Nilsson (2016) investigated the observations in Scania, Sweden, and showed that the price effect of proximity to a commuter train station was strongest in lower price segments of the housing market in comparison to higher price segments. Sun et al. (2016) in Tianjin, China, concluded that the construction of subway lines had a greater impact on marginal zones of the city than on the city's downtown region because of the extent and quality of public transportation available in those regions.

Regarding Tehran, Forouhar and Hasankhani (2018) investigated whether the effects of the metro station to the residential properties are different in higher income districts and lower income districts. They explored the effect of opening 6 metro stations on housing prices, where three were in highincome prosperous regions and the other three were in low-income deprived regions. Using only 30 transactions per year for each of those 6 stations (and total of 2,160 observations), they claim that after opening the metro station in the high-income regions, property prices around the metro station will fall in price, while it rises in low-income regions. 
Even though most of the papers estimate that the impact of new rapid rail transportation on housing price is positive, but some of the researches show that this impact is negative or insignificant when the property is very close to the stations. Diao et al. (2016) found that removal of train noise externalities increases housing prices in the affected region by $13.7 \%$ on average after the cessation period of the KTM railway services in Singapore. The average prices for houses located within a 400-m boundary from the railway lines increased by 3.5\% relative to prices for houses located outside the $400-\mathrm{m}$ boundary after the cessation agreement has been announced. Mohammad et al. (2015) estimated that the effect of the newly operated Dubai Metro on the sale transaction value of residential properties was about $-9 \%$ within $0.5 \mathrm{~km}$ of a station because of noise and pollution from the transport system.

Ransom (2018) implements the same type of analysis, i.e., difference-in-difference regression technique, as ours in a very similar research question to study the effect of light rail transit service. Their results suggest no significant value added by the light rail services to the residential neighborhoods in Seattle, Washington. Billings (2011) for Charlotte, North Carolina, also found that the impact of the LRT on the value of residential properties was not significant within 0.8 kilometer. Bowes and Ihlanfeldt (2001) investigated this effect in Atlanta, Georgia and found that houses that are very close to stations were affected by negative externalities emitted by stations and the access to neighborhoods that stations provide to criminals, but those at further distance were beyond the externality effects and benefited from the transportation, like access provided by the stations, reducing commuting costs or by attracting retail activity to the neighborhood. Their result showed that properties within a $500 \mathrm{~m}$ from a rail station are $19 \%$ cheaper than properties beyond $5 \mathrm{~km}$ from a station. Giuliano (2004) studied the effect of San Francisco rail transit system (BART) on urban form and found out that it did not have much an effect, and it was not an important factor in the location decision of employers. Forrest et al. (1996) studied the effect of rail services on house prices in Manchester and found a significant negative effect.

In one of the few studies conducted on commercial properties, Mohammad et al. (2015) estimated the effect of the newly operated Dubai Metro on the sale transaction value of residential and commercial properties. These estimates showed a positive effect of the metro on sale values of both residential and commercial properties, although the effect was stronger for commercial properties. Baker (1983) studied the relationship between land development and train station and found out that $54 \%$ of nonresidential construction occurred close to train station in Washington DC in period of 1979-1982. In a state-of-the-art paper, Pope and Pope (2015) study the effect of Walmart opening on housing prices, and their estimates suggest that a new store increases nearby housing prices.

On the other hand, transportation including metro railway or Bus Rapid Transit (BRT) can have a widespread effect on the other urban amenities. Stewart et al. (2017) investigate the causal effect of Bus Rapid Transit (BRT) on changes in transit ridership. The result denote that Ridership increased by $35 \%$ along routes where BRT was implemented from 2010 to 2013 compared to routes that maintained conventional bus service. Yang and Shyr (2019) study the effect of bus accessibility on property prices in Ximen, China and conclude that access to bus stop is positively correlated with property prices.

On the methodological perspective, while this paper and most of the papers in this literature use reduced form techniques for estimation, a recent line of research addresses the spatial structure of cities directly with formal, structural models. Bryan et al. (2019) reviews benefits of such models in the far more fluid cities of developing world.

\section{Data}

Three categories of data are required to investigate the effect of the inauguration of the metro station on housing prices: $i$ ) housing prices; $i$ ) metro stations and their inauguration date; $i i i$ ) postal codes and geographical coordinates. Each category is described in detail. 


\subsection{Housing Prices}

Data on housing prices are according to the recorded transactions, obtained from the Office of Planning and Housing Economy (OPHE) of the Ministry of Roads and Urban Development in Iran. This administrative information includes complete data on all individual housing transactions from April 1, 2010, to December 20, 2018 (nine years) in Iran. We focus on part of data which is for the residential housing transaction in Tehran, which consists of almost 1,260,000 housing sale transactions. All real estate transactions in Iran are done by real estate agencies. These transactions must be fully integrated into a system connected with the Ministry of Roads and Urban Development. The system has been in operation throughout the country since 2010. The information recorded within the system is provided by real estate managers. OPHE record all the housing transaction information which are officially registered in real estate agencies since $2010^{2}$. We refer to Appendix 2 for data cleaning steps. For each transaction, the OPHE data has the following variables, and the summary statistics is reported in Table (1). The description of the time categories is presented in the appendix.

1. Transaction code,

2. The transaction dates,

3. Total transaction price,

4. The price per square meter,

5. The surface area of the house,

6. Age of the building,

7. Using type of the building,

8. Frame type of the building skeleton,

9. The first six digits of the ten digits postal code of the housing traded,

10. Percentage of the property traded.

The using type of the building in our administrative data is divided in 4 categories: $i$ ) Residential Buildings ii) Commercial Buildings iii) Institutions iv) Office Buildings. More than $99 \%$ of these transactions are residential houses. In this research, we calculate the impact of metro station inauguration on residential houses and omit the other types of building which are less than $1 \%$.

Table 1: Summary statistics of residential properties' valuables

\begin{tabular}{lcccccc}
\hline & \multicolumn{2}{c}{ Total } & \multicolumn{2}{c}{ Treatment } & \multicolumn{2}{c}{ Control } \\
& mean & sd & mean & sd & mean & sd \\
\hline Area & 84.93 & 38.30 & 76.58 & 33.41 & 84.89 & 40.56 \\
Price (Mill. Tomans) & 4.24 & 3.48 & 3.66 & 2.74 & 4.25 & 3.49 \\
Price (Dollars) & 1000.95 & 613.69 & 881.19 & 501.85 & 1007.79 & 628.66 \\
Age & 8.82 & 8.59 & 10.12 & 9.37 & 9.08 & 9.02 \\
\hline Observations & $1,267,466$ & & 66,324 & & 766,958 \\
\hline
\end{tabular}

Comments: USD/IRR changes in different years. In 2010 each Dollar was averagely 1100 Tomans and in 2019 it grows up to 12000 Tomans in the market. Prices are nominal and are not adjusted for inflation. Treatment and control groups are introduced later in Section 4.3 of the paper.

As shown in the Table (2), the skeleton is mostly made of concrete, metal or both. Only less than $1 \%$ of skeleton properties are different.

Residential properties in Iran and Tehran are one or more units in one building, each unit having one household and owner. In this situation, several families may live in one apartment. There are, of course, single-unit duplex houses that are very few. Each residential property in Iran is divided into 6

\footnotetext{
${ }^{2}$ The housing information used in this article is available in the following link: https://bit.ly/2IteOEz
} 
Table 2: Summary statistics by frame type of residential properties

\begin{tabular}{lrrr}
\hline & Count & Col \% & Cum \% \\
\hline Frame Type & & & \\
Concrete & 609,141 & 48.1 & 48.1 \\
Steel & 584,520 & 46.1 & 94.2 \\
Steel and Concrete & 69,396 & 5.5 & 99.7 \\
Without Frame & 2,738 & 0.2 & 99.9 \\
Brick or Cement Block & 1,091 & 0.1 & 100.0 \\
Wood & 317 & 0.0 & 100.0 \\
Adobe or Clay & 262 & 0.0 & 100.0 \\
\hline Total & $1,267,466$ & 100.0 & \\
\hline
\end{tabular}

Comments : More than 99 percent of frame types are concrete or/and metal.

shares, where any real or legal person can own one or more of these shares, but generally one person owns all 6 shares. At the time of trading, any of these shares can be traded. As a result, 16\%,33\%,50\% $, 67 \%, 84 \%$ and $100 \%$ of a property may be traded on each transaction. In the administrative OPHE data, the number of transactions that is traded less than $100 \%$ of the house is only $1.7 \%$, so they are omitted from our study.

\subsection{Metro Stations}

The metro stations data has been obtained from Tehran Metro Operations Company. This information includes:

1. Time of the inauguration of the metro station,

2. Geographic coordinates of the metro station,

3. Name of the metro station,

4. The number of metro lines which passes through the station.

The total number of stations operated in Tehran is 105 , which is planned to increase up to 150 stations by 2022 . The number of stations opened during the period considered in this study is presented in Figure (1). The red lines specify the stations opened within our research period.

As will be discussed further, we use difference-in-difference method to investigate the causal effect of a metro station inauguration on residential housing prices. To implement this method, it is necessary to have access to the data before and after the inauguration of the metro station. Based on the availability of housing prices from April 1, 2010, only those stations inaugurated after this date have been investigated. Therefore, 45 stations are investigated, most of which are related to stations of lines $\mathrm{C}$ and $\mathrm{D}$.

It is important to mention that four of these stations $(\mathrm{A} 1, \mathrm{~A} 8, \mathrm{~B} 9, \mathrm{D} 1)$ have been inaugurated two times because they are the junctions of two different metro lines. These stations opened for the first time before the period under investigation, and for the second time within our research period. Since the second opening of metro station can have a different impact from the first opening, we produce two different outputs: with and without these stations. Location of these 45 stations investigated is depicted on Figure (2).

\subsection{Postal Codes and Geographic Coordinates}

In Iran, each property has a unique 10-digit postal code that not only identifies the city and neighborhood of the property but also its exact geographic coordinates. Postal code in Tehran begins with numbers 11 to 19 (excluding 12). According to the first three digits of the postal code, the city of 


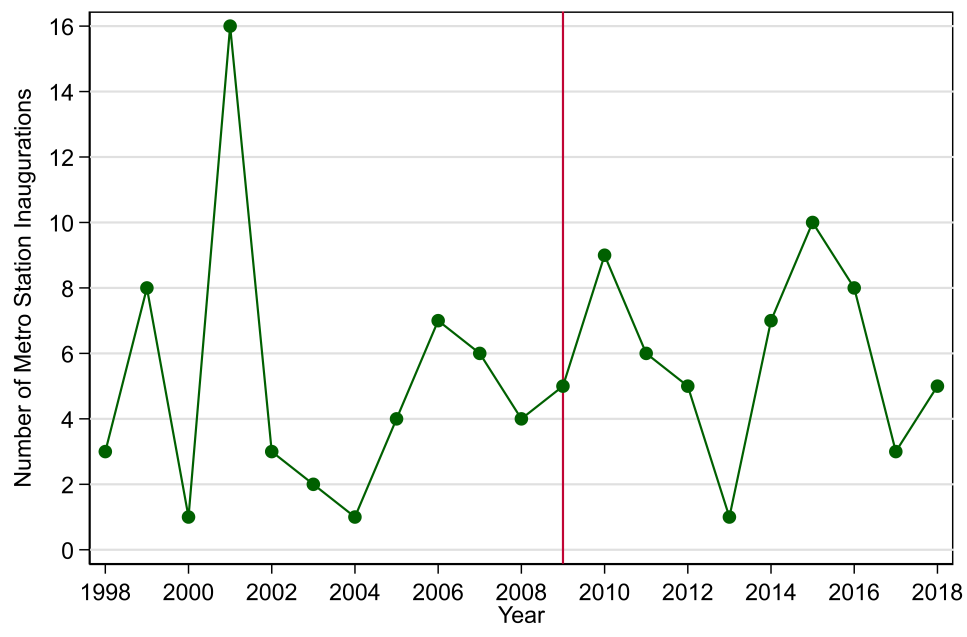

Figure 1: Number of inaugurated stations per year in Tehran since 1998. The vertical line at 2009 depicts the earliest transaction that is recoreded in OPHE administrative data. Source: Reported by Tehran Metro Operations Company

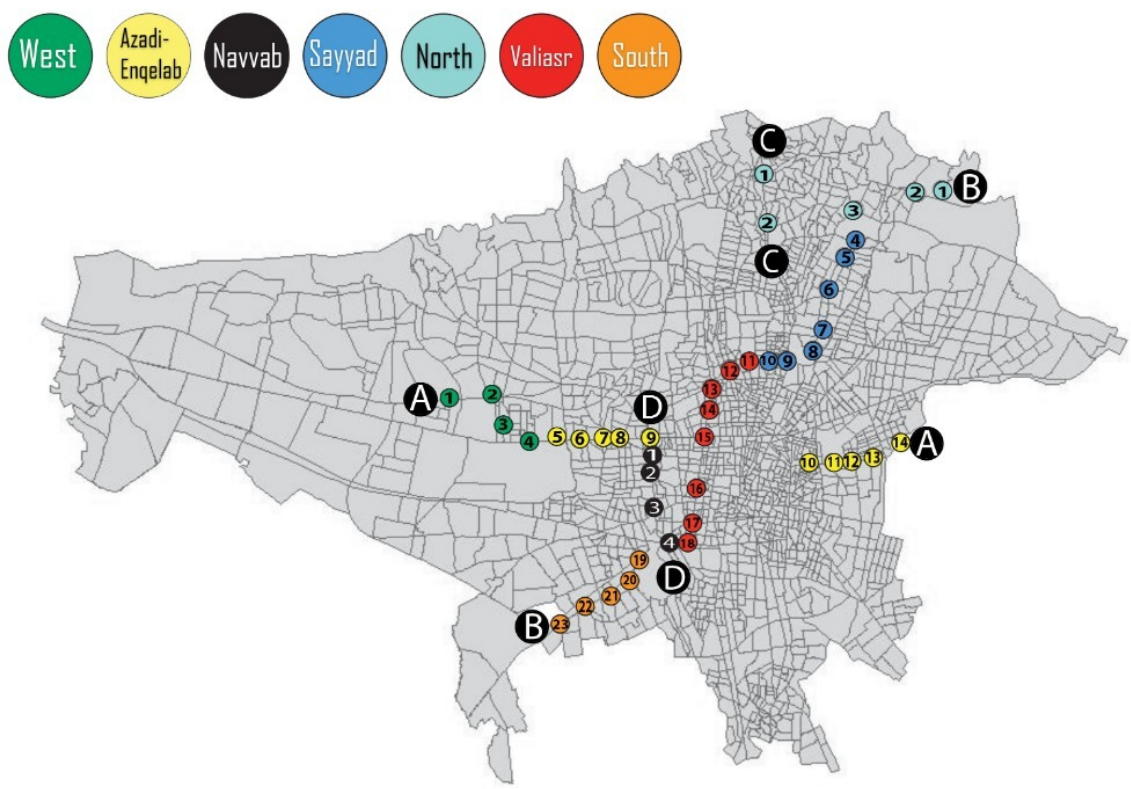

Figure 2: Location of intended stations of Tehran's metro rail system

Tehran is divided into 65 regions. The first five and six digits of the postal code, the city of Tehran is divided into 1,877 and 15,016 parts respectively.

Polygons created by the first 5 digits of the postal code are visible on map of Tehran city in Figure (2) and (3). Figure (3) represents number of sales in each of the 5-digit regions during our study. The common (equivalent) geographic coordinates for all properties inside a polygon with the same first six digits of postal code is considered the geographic coordinates of the polygon center. The instruction on the conversion of the postal code to the geographical coordinates is taken from the National Post Office of the Islamic Republic of Iran. At first, we converted the postal code to the geographical 
coordinates, after that we have calculated distances between traded houses and metro stations. This distance represents the length of the straight line between the two points and represents the Euclidean distance. We refer to Appendix 1 for more details. In some parts of northern Tehran, the received postal code data were not accurate with the accuracy of 6 digits, therefore 5-digit postal codes are used instead of a 6-digit postal code.

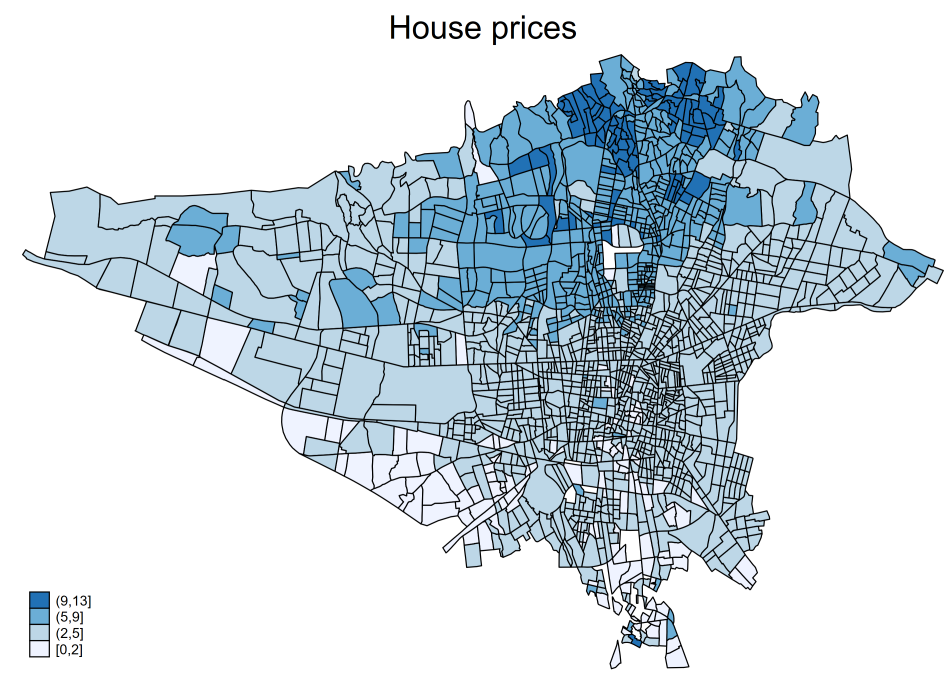

Figure 3: Distribution of Average Housing Price in Tehran

\subsection{Data Limitations}

There are shortcomings in the collected data that potentially may lead to a lower precision of estimates. These limitations are:

- Postal codes: Obtained data have only the first six digits of postal code because of the confidentiality of the information. Therefore, the exact coordinates of each house are not available. Further, in the post office databases, some of these 6-digit postal codes did not have geographical coordinates, therefore, for this group, a 5-digit code was used instead of 6 digits, so that we can convert them to geographical coordinates.

- Altitude: Only latitude and longitude are involved in calculating the distance, and the information on the difference in elevation between the points is not available. This issue also causes a measurement error, because Tehran is in the Alborz mountain range, and its highest and lowest elevations are respectively 1800 meters and 900 meters above the sea level.

- Euclidean distance: Due to the pathways and obstacles that exist on the surface of the city, the path between the property and the metro may be a broken path, and the Euclidian distance may not be appropriate. In the other sense, the distance should be considered as the length of the shortest path between the two points based on the network of streets and roads and in general, the routes that can be traversed either ride or walk. In other words, the straight line between the two points may be very short, but the path from one to another is far longer. However, regarding the available data and information, it was not possible in this research to calculate the network distance.

- Ahead of inauguration effects: The opening of a metro station has various phases, including the decision to open it by the authorities, the official announcement, the start of the station construction, and finally, the official opening of the station. Here, only the official opening of the station is considered, and its effect on the price of housing is examined, while other phases may have a significant impact in this respect. Therefore, our estimate should be interpreted as a lower 
bound and needs to be adjusted of the effects of metro from the announcement of construction to the time of operation.

- Prices downward bias: Due to the tax concerns of the property owners, under reporting of prices is possible. The information recorded within the system is provided by real estate managers, so in some cases it is possible that the price of housing may not be reported in real value and that the price of housing may be lower due to tax evasion. Potentially, this issue can affect the results, as it is more probable that owners in the more expensive properties in the north of Tehran misreport more. However, it seems that people who live in the same region are homogeneous in this regard. It is reasonable to assume that any such bias remains constant over time. Therefore, the effect of this bias before and after metro station inauguration will be controlled for by the region fixed effect that will be introduced in the next section.

\section{Methodology}

In this section, we review the questions and hypotheses that we want to investigate, then we explain and build the identification method that would be appropriate for these hypotheses and ultimately we express the model specification and define variables.

\subsection{Hypotheses}

The main advantage of metro station is a better accessibility to public transportation. Therefore, it is expected that housing prices will grow significantly at the margins of the city with less public transportation because of the opening of the metro. In contrast, we expect not to witness a significant impact on housing prices in the city center and around streets having access to different modes of public transportation abundantly. Based on these, we define three hypotheses below:

- Hypothesis 1: In Tehran, the opening of a metro station, on average, causes the price of the properties around it to increase.

- Hypothesis 2: In Tehran, the opening of a metro station for the second time does not have a significant effect on the price of the properties around it.

- Hypothesis 3: In Tehran, the opening of a metro station in different regions has a different effect on the price of the properties such that this effect is less for regions with more public transport.

\subsection{Identification Method}

As depicted in the appendix Table (12), the overall trend of nominal housing prices in Tehran has been increasing. It implies that after the opening of stations prices are likely to be higher than before. But apparently this increase shall not be interpreted as the causal effect of the opening of metro station. To examine our assumptions, it is necessary to have a model which can accurately identify the net impact of the metro station opening on housing prices. Difference-in-difference is the method we use to address this issue.

Difference-in-difference method is one of the main methods of identification in econometrics. In fact, in the realm of identification, we seek a causal effect of explanatory variables that is exogenous and does not have endogeneity with dependent variable. Endogeneity may arise from three sources: i) reverse causality; $i$ ) common factors and omitted variable bias; iii) measurement error. To check the endogeneity, we observe that the price of housing does not affect the metro location, so there is no reverse causality problem. Inflation is one possible confounding factor that is taken care of using time fixed effects within diff-in-diff framework. Moreover, our data may have many possible measurement errors. For instance as exact location of the houses are not reported, our measure of distance to the nearest metro station is not accurate. For more information regarding the measurement error we had a thorough discussion in Section 3.4. 
To follow natural experiment, as defined in economics, we need to divide the sample (target) population into two groups of test and control. The experiment affects only the test group, but other factors affect both test and control groups similarly. Therefore, to find the net effect of a natural experiment, it is enough to compare the difference between the outputs of these two categories. We consider houses located at a distance less than 400 meters from a metro station to be the test group and, the houses located at 400 meters to 3 kilometers from the metro station to be the control group.

\subsection{Specification}

The primary statement for each transaction $i$ takes place in time $t$ is as follows:

$$
\ln \text { price }_{i t}=\alpha+\beta_{1} \text { Treat }_{i t}+\beta_{2} \text { Post }_{i t}+\beta_{3}\left(\text { Treat }_{i t} \times \text { Post }_{i t}\right)+\varepsilon
$$

By adding other control variables, the full statement is completed as follows:

$$
\begin{aligned}
\ln \text { Price }_{i t}= & \alpha+\beta \mathrm{T}_{i t}+\gamma \mathrm{M}_{i t}+\delta\left(\mathrm{T}_{i t} \times \mathrm{M}_{i t}\right) \\
& +\delta_{\text {region }}+\delta_{\text {quarter }}+\theta\left(\delta_{\text {region }} \times \delta_{\text {quarter }}\right) \\
& +\gamma_{1} \text { age }_{i t}+\gamma_{2} \text { age }_{i t}^{2}+\lambda_{1} \text { area }_{i t}+\lambda_{2} \text { area }_{i t}^{2}+\varepsilon_{i t}
\end{aligned}
$$

In the above equation, $\delta$ is the difference-in-difference coefficient of interest, which indicates the effect of the opening of the metro station on its neighboring properties relative to the farther properties. Now, we introduce each of the variables used in the model.

Logarithm of price (Ln Price): The dependent variable in this statement is the logarithm of nominal price of the sold property. We use the logarithm of housing prices rather than the actual values because, as it is well known in economics, density of prices is non-negative and pretty much skewed to the right, while the density of logarithm of prices are more similar to the normal distribution. Moreover, notice that we work with nominal prices throughout the paper.

Age of building (Age): The administrative OPHE data also reports the age of building for each transaction, which has been considered an effective variable on housing prices.

The surface area of property (Area): In addition to the age of the buildings, the area was also available in housing price data, so this variable is also considered an effective variable on housing prices. Given the importance of the two variables of age and area of building, a summary of the statistical data on the number of housing transactions based on the age and area of the building has been reported in Table (3).

$\mathbf{M}$ (Treat): This dummy variable takes values 0 and 1 , and it is defined to determine the distance of each traded property to the nearest metro station. If the distance between the nearest metro station and the property is less than 400 meters, the value of this variable is set to 1, and if the distance is from 400 meters to 3 kilometers, the value of this variable is set to 0 . This variable is defined for each transaction as follows:

$$
\mathrm{M}_{i t}=\left\{\begin{array}{cc}
0 & \text { Far from station }(400 \mathrm{~m}-3 \mathrm{~km}) \\
1 & \text { Near the station }(0-400 \mathrm{~m})
\end{array}\right.
$$

Table (1) reports summary statistics of age, surface area and price of each transaction for the treatment group as well as the control group.

$\mathbf{T}$ (Post): This variable also takes values 0 and 1 , and it is defined to determine the transaction time of each traded property reference to the opening time of the nearest metro station. If the transaction time is after the opening of the nearest metro station, its value is set to 1 , and if the transaction time is before the opening of the nearest metro station, it takes 0 . This variable is defined associated with each transaction.

$$
\mathrm{T}_{i t}=\left\{\begin{array}{l}
0 \text { Before openning } \\
1 \text { After openning }
\end{array}\right.
$$


Table 3: Summary statistics by age and surface area of residential properties

\begin{tabular}{|c|c|c|c|c|c|c|c|c|c|c|c|c|}
\hline & \multicolumn{12}{|c|}{ Age (years) } \\
\hline & \multicolumn{2}{|c|}{$0-5$} & \multicolumn{2}{|c|}{$5-10$} & \multicolumn{2}{|c|}{$10-15$} & \multicolumn{2}{|c|}{$15-20$} & \multicolumn{2}{|c|}{ More than 20} & \multicolumn{2}{|c|}{ Total } \\
\hline & $\begin{array}{r}\text { Col } \\
\%\end{array}$ & $\begin{array}{r}\text { Row } \\
\%\end{array}$ & $\begin{array}{r}\text { Col } \\
\%\end{array}$ & $\begin{array}{r}\text { Row } \\
\%\end{array}$ & $\begin{array}{r}\text { Col } \\
\%\end{array}$ & $\begin{array}{r}\text { Row } \\
\%\end{array}$ & $\begin{array}{r}\text { Col } \\
\%\end{array}$ & $\begin{array}{r}\text { Row } \\
\%\end{array}$ & $\begin{array}{r}\text { Col } \\
\%\end{array}$ & $\begin{array}{r}\text { Row } \\
\%\end{array}$ & $\begin{array}{r}\mathrm{Col} \\
\%\end{array}$ & $\begin{array}{r}\text { Row } \\
\%\end{array}$ \\
\hline \multicolumn{13}{|l|}{ Area (meters) } \\
\hline $0-50$ & 7.9 & 29.0 & 12.6 & 22.6 & 17.3 & 27.1 & 15.8 & 15.1 & 7.1 & 6.1 & 11.3 & 100.0 \\
\hline $50-100$ & 60.4 & 39.7 & 66.8 & 21.5 & 66.6 & 18.8 & 68.1 & 11.8 & 53.2 & 8.2 & 62.9 & 100.0 \\
\hline $100-200$ & 29.8 & 51.2 & 19.2 & 16.2 & 15.0 & 11.1 & 15.0 & 6.8 & 36.3 & 14.7 & 24.0 & 100.0 \\
\hline $200-400$ & 1.9 & 45.5 & 1.4 & 16.4 & 1.1 & 11.4 & 1.1 & 6.9 & 3.4 & 19.7 & 1.7 & 100.0 \\
\hline More than 400 & 0.0 & 37.6 & 0.0 & 25.7 & 0.0 & 9.2 & 0.0 & 5.5 & 0.0 & 22.0 & 0.0 & 100.0 \\
\hline Total & 100.0 & 41.3 & 100.0 & 20.2 & 100.0 & 17.8 & 100.0 & 10.9 & 100.0 & 9.8 & 100.0 & 100.0 \\
\hline
\end{tabular}

Comments: In each cell, the first number illustrates percentage of traded houses by age category and the second one illustrates the percentage of traded houses by surface area category. For instance, $51.2 \%$ of houses with 100-200 square meter area, are 5 or less than 5 years old and among houses younger than 5 years, only $29.8 \%$ have area between 100 and 200 square meter.

Region: This variable is used to control location fixed effects to trace various changes that may occur in each region of the city. For each transaction, this variable takes the first three digits of the corresponding postal code. In total, Tehran is divided into 63 regions based on the first three digits of the postal codes of the properties. In other words, $62(=63-1)$ dummy variables are included to the main specification, each of which is one for only one of the 3-digit postal codes and is zero otherwise.

Time: This variable is also considered to capture the fixed effects associated with the quarter of transactions. Our data span over 33 quarters. In other words, we include 32 dummy variables in our specification. Notice that inclusion of these quarter fixed effects is very important to control for the fact that house prices in Tehran have time trend and we use nominal house prices.

$\mathbf{T}^{*} \mathbf{M}$ : The coefficient of this variable, denoted by $\beta_{3}$, is the result of the difference-in-difference model that is the output of this research.

Time*Region: This variable also acts as a time- and region-controlling variable to capture the effects of the events occurring at different times and regions.

\section{Results}

In this section, we present the regression results. We also investigate the robustness check of treatment and control groups by testing different values in the appendix.

\subsection{Average Effect of Metro Stations}

We start by considering the distance between the property's location and the nearest metro station, setting 1 for those whose distance is less than 400 meters and 0 for those with distance more than $400 \mathrm{~m}$ and less than $3 \mathrm{~km}$ to the nearest metro station. In this way, we classify all transactions around the stations into two groups, the test group (with value 1 ) and the control group (with value 0 ). This case results in the value of $R^{2}$ of $75 \%$ which is highest value among different settings. In this way, as shown in Table (4), we find that, on average, nearby properties, after the opening of the station, face a $3.7 \%$ more growth of the price than those in farther distances ${ }^{3}$.

\footnotetext{
${ }^{3}$ The total number of housing transactions, as it said in the previous sections, was about 1,260,000 instances. However, about 427,000 properties were located at distances more than $3 \mathrm{~km}$ from all the opened stations. Consequently, the regression sample consisted of 833,000 transactions.
} 
It can be argued that the increase in housing prices is a combined effect of metro station inauguration and change in usage of houses around metro station. We believe this is not the case in the city of Tehran as the stations opened in the period of our analysis are located in regions that have a persistent structure in type of usage of buildings and this concern cannot significantly affect our results.

Table 4: Regression results for average effect of metro station

\begin{tabular}{|c|c|c|c|c|c|}
\hline & $(1)$ & $(2)$ & (3) & $(4)$ & $(5)$ \\
\hline $\mathrm{T}=1$ & $\begin{array}{c}0.5941^{* * *} \\
(0.0015)\end{array}$ & $\begin{array}{c}-0.0123^{* * *} \\
(0.0013)\end{array}$ & $\begin{array}{c}-0.0172^{* * *} \\
(0.0012)\end{array}$ & $\begin{array}{c}-0.0202^{\text {*** }} \\
(0.0012)\end{array}$ & $\begin{array}{c}-0.0248^{* * * *} \\
(0.0015)\end{array}$ \\
\hline$M=1$ & $\begin{array}{c}-0.0457^{* * *} \\
(0.0037)\end{array}$ & $\begin{array}{c}0.0122^{* * *} \\
(0.0022)\end{array}$ & $\begin{array}{c}0.0180^{* * *} \\
(0.0021)\end{array}$ & $\begin{array}{c}0.0228^{* * *} \\
(0.0021)\end{array}$ & $\begin{array}{c}0.0139^{* * * *} \\
(0.0021)\end{array}$ \\
\hline $\mathrm{T}=1 * \mathrm{M}=1$ & $\begin{array}{l}0.0105^{*} \\
(0.0053)\end{array}$ & $\begin{array}{c}0.0236^{* * *} \\
(0.0031)\end{array}$ & $\begin{array}{c}0.0247^{* * *} \\
(0.0030)\end{array}$ & $\begin{array}{c}0.0226^{* * *} \\
(0.0029)\end{array}$ & $\begin{array}{c}0.0371^{* * *} \\
(0.0030)\end{array}$ \\
\hline Age (centuries) & & & $\begin{array}{c}-1.1762^{* * *} \\
(0.0046)\end{array}$ & $\begin{array}{c}-2.5029^{* * *} \\
(0.0125)\end{array}$ & $\begin{array}{c}-2.5031^{* * *} \\
(0.0125)\end{array}$ \\
\hline Area (Hectares) & & & $\begin{array}{c}16.9128^{* * *} \\
(0.1210)\end{array}$ & $\begin{array}{c}10.2480^{* * *} \\
(0.3469)\end{array}$ & $\begin{array}{c}10.7196^{\text {*** }} \\
(0.3442)\end{array}$ \\
\hline $\operatorname{Age}^{2}$ (centuries) & & & & $\begin{array}{c}4.1766^{* * *} \\
(0.0354)\end{array}$ & $\begin{array}{c}4.1717^{* * *} \\
(0.0352)\end{array}$ \\
\hline Area $^{2}$ (Hectares) & & & & $\begin{array}{c}1.279 \times 10^{2 * * *} \\
\quad(12.3798)\end{array}$ & $\begin{array}{c}1.143 \times 10^{2 * * *} \\
\quad(12.2858)\end{array}$ \\
\hline Constant & $\begin{array}{c}0.8337^{* * *} \\
(0.0012)\end{array}$ & $\begin{array}{l}-0.0478 \\
(0.0421)\end{array}$ & $\begin{array}{l}-0.0261 \\
(0.0401)\end{array}$ & $\begin{array}{c}0.0407 \\
(0.0417)\end{array}$ & $\begin{array}{l}-0.0441 \\
(0.2509)\end{array}$ \\
\hline Region & No & Yes & Yes & Yes & Yes \\
\hline Quarter & No & Yes & Yes & Yes & Yes \\
\hline Frame & No & No & No & Yes & Yes \\
\hline $\mathrm{N}$ & 833,282 & 833,282 & 833,282 & 833,281 & 833,281 \\
\hline R-squared & .1683 & .7155 & .742 & .7466 & .7524 \\
\hline
\end{tabular}

Standard errors in parentheses

${ }^{*} p<0.05,{ }^{* *} p<0.01,{ }^{* * *} p<0.001$

Comments: Regression number (1) has no control variable and regression number (5) uses all existing control variables and fixed effects. As specified in the table, by adding control variables, the value of $r^{2}$ goes to $75.2 \%$. The post, treat variables are defined as the time and place dummy variables.

\subsection{Inauguration of the Metro Station for the Second Time}

To test the second hypothesis, those stations that have been opened for the second time during the study are examined separately. The last column of Table 7 considers only those four stations and shows that the coefficient is not statistically different from zero. These results indicate that those stations 
opened for the second time due to connection of a new line, do not have a significant impact on the prices of the properties near them. In other words, these stations have had their impact on the housing prices after their initial opening.

We also estimate the primary regression without the four re-opened stations in Table 7. The coefficients of the case of considering all 45 stations together and the case of removing of four stations opened for the second time can be compared. As it can be seen including/excluding the four re-opened stations does not affect the statistical significance of the coefficients. ${ }^{4}$

Table 5: Regression results to test the effect of opening the station for the second time

\begin{tabular}{|c|c|c|c|}
\hline & $\begin{array}{c}(1) \\
45 \text { Stations }\end{array}$ & $\begin{array}{c}(2) \\
\text { 41 Stations }\end{array}$ & $\begin{array}{c}(3) \\
4 \text { Stations }\end{array}$ \\
\hline $\mathrm{T}=1$ & $\begin{array}{c}-0.0248^{* * *} \\
(0.0015)\end{array}$ & $\begin{array}{c}-0.0233^{* * *} \\
(0.0017)\end{array}$ & $\begin{array}{c}-0.0243^{* * *} \\
(0.0072)\end{array}$ \\
\hline$M=1$ & $\begin{array}{c}0.0139^{* * *} \\
(0.0021)\end{array}$ & $\begin{array}{c}0.0164^{* * *} \\
(0.0023)\end{array}$ & $\begin{array}{c}-0.0178^{* *} \\
(0.0058)\end{array}$ \\
\hline $\mathrm{T}=1 * \mathrm{M}=1$ & $\begin{array}{c}0.0371^{* * *} \\
(0.0030)\end{array}$ & $\begin{array}{c}0.0388^{* * *} \\
(0.0032)\end{array}$ & $\begin{array}{l}-0.0005 \\
(0.0083)\end{array}$ \\
\hline Age (centuries) & $\begin{array}{c}-2.5031^{\text {*** }} \\
(0.0125)\end{array}$ & $\begin{array}{c}-2.5244^{* * *} \\
(0.0135)\end{array}$ & $\begin{array}{c}-2.5746^{* * *} \\
(0.0314)\end{array}$ \\
\hline Area (Hectares) & $\begin{array}{c}10.7196^{* * *} \\
(0.3442)\end{array}$ & $\begin{array}{c}13.8140^{* * * *} \\
(0.3653)\end{array}$ & $\begin{array}{c}-17.5511^{* * *} \\
(1.1811)\end{array}$ \\
\hline $\operatorname{Age}^{2}$ (centuries) & $\begin{array}{c}4.1717^{* * *} \\
(0.0352)\end{array}$ & $\begin{array}{l}4.2409^{* * *} \\
(0.0381)\end{array}$ & $\begin{array}{l}4.1220^{* * *} \\
(0.0908)\end{array}$ \\
\hline Area $^{2}$ (Hectares) & $\begin{array}{c}1.143 \times 10^{2 * * *} \\
(12.2858)\end{array}$ & $\begin{array}{c}3.212 \times 10^{*} \\
(12.8276)\end{array}$ & $\begin{array}{c}9.903 \times 10^{2 * * *} \\
(48.9493)\end{array}$ \\
\hline Constant & $\begin{array}{l}-0.0441 \\
(0.2509)\end{array}$ & $\begin{array}{l}-0.0564 \\
(0.2533)\end{array}$ & $\begin{array}{c}0.3082 \\
(0.1760)\end{array}$ \\
\hline $\mathrm{N}$ & 833,281 & 725,519 & 107,762 \\
\hline R-squared & .7524 & .7542 & .7396 \\
\hline
\end{tabular}

Standard errors in parentheses

${ }^{*} p<0.05,{ }^{* *} p<0.01,{ }^{* * * *} p<0.001$

Comments: In regression number (1), all stations are considered and in regression number (2) 4 stations that have been opened for the second time have been removed. The (post $\times$ treat) factor in these two situations is roughly equal, indicating no appreciable effect on housing prices at the time of the second opening of the station

\footnotetext{
${ }^{4}$ Notice that the diff-in-diff coefficient $($ Post $\times$ Tr eat $)$ in the two cases $(3.71 \%$ and $3.88 \%)$ are economically close, but statistically different, so we make no claim about the equivalence of columns 1 and 2 in Table (5).
} 


\subsection{Clustering Stations}

In this section, we divide stations based on their urban differences, and test the third hypothesis. We will explain each of these cases below.

- North (B1-B3 and C1-C2): Stations located in the North of Tehran are in this category. One of the characteristics of this category is that household income in these regions is higher than the average of the community and less public transport than the city center.

- South (B19-B23): Stations located in the south of Tehran are in this category. Regarding the weak economic conditions in the south of Tehran, it is expected that the property prices near these metro stations will improve.

- West (A1-A4): The common characteristic of these stations is that they are all on the western margins of Tehran, and the metro is one of the most important vehicles for transportation of the residents of this region. Therefore, it is anticipated that the opening of the metro station in this region will have a positive impact on the price of housing around it.

- Sayyad (B4-B10): Due to the lack of a BRT line and the stations of other metro lines, it is expected that the opening of metro stations in this region will have a positive impact on the property prices around it.

- Azadi - Enqelab (A5-A14): Again, regarding the presence of the BRT line, which was operated before 2010, it is expected that the opening of metro stations on these streets will not have much impact on the property prices around it.

- Vali Asr (B11-B18): Regarding the existence of the BRT line, which was implemented before 2010, it is expected that the opening of metro stations on this street will not have much effect on the property prices around it.

- Navvab (D1-D4): Regarding the presence of the BRT line in this street, which was operated before 2010, it is predictable that the opening of metro stations on these streets will not have a positive effect regarding public transport access for the properties around it. It should be noted that these stations belong to line 7 of the Tehran Metro, which have recently been operated in 2018. Based on the literature reviewed earlier, we conjecture that the negative effects, e.g., disturbance, noise, crime rates, and pollution have contributed to the negative coefficient.

Results of the regression analysis for each of these categories are reported in Table (6) which indicates that those stations opened in regions with access to bus rapid transit (BRT) lines did not have a significant effect on the prices of the properties around it. We interpret this finding as follows: Advantage of having access to the metro station that causes the prices of the region's properties to be raised after the opening of the metro station is more and faster access to the rest of the city. Therefore, properties with good access to BRT lines and already easy access to city center, we find less than 2 percent effect on their prices. Categories 5, 6, and 7 have the same status.

Unlike the categories described in the previous paragraph, the properties located in Tehran's peripheral regions (north, northeast, west, and south) had a growth of prices from 2 to $11 \%$ at the time of opening of these stations. The most significant price increase is identified for the properties around the stations in the north of Tehran that includes Tajrish and Mahallati stations. These stations are in more affluent part of the city and while there is good access to well developed highways, there is relatively less public transportation in these regions, therefore the opening of the metro station in these regions cause the price of the surrounding properties to increase. The least increase is found for properties around the Sayyad highway (No.4). 


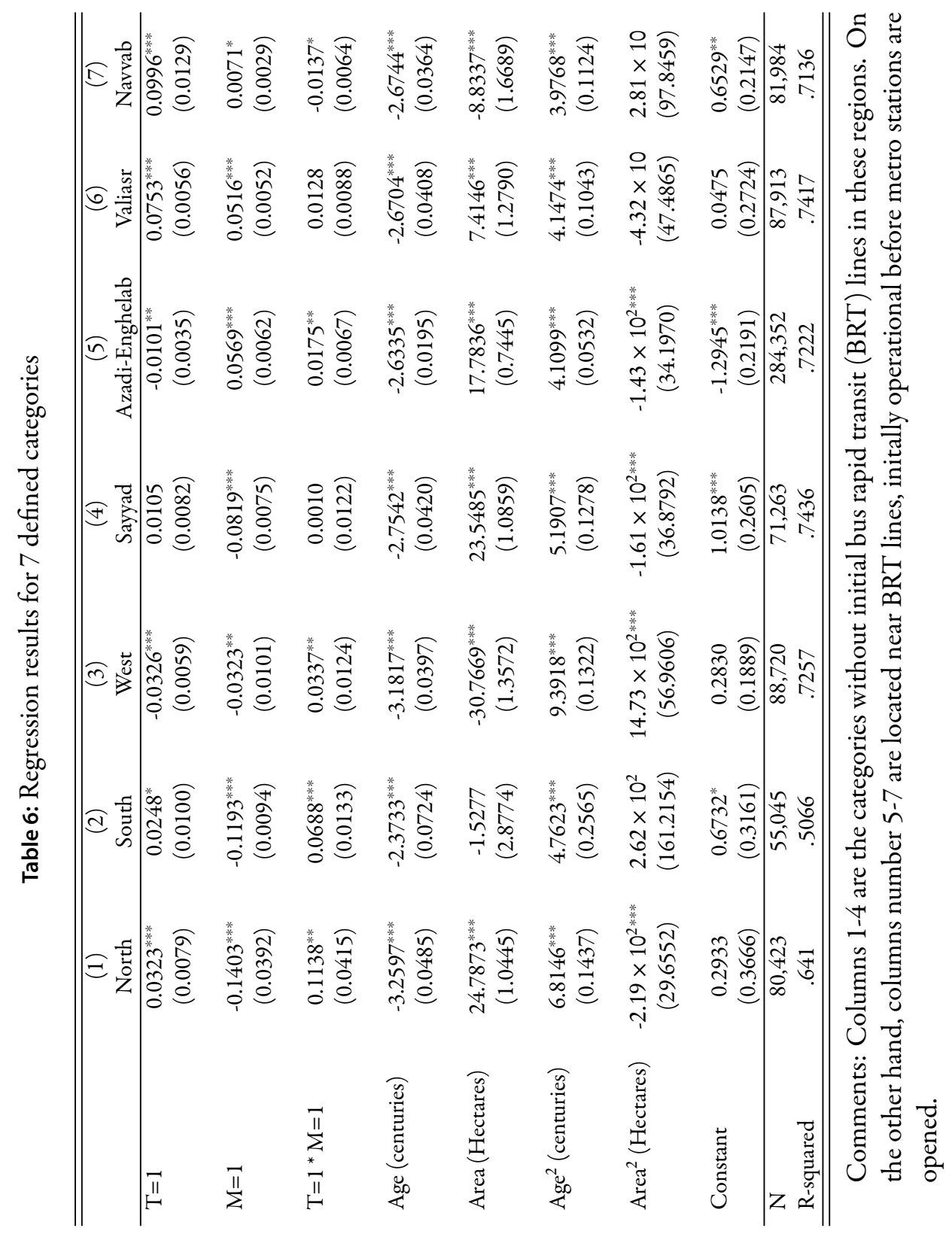




\section{Conclusion}

In this paper, using a unique administrative data of transacted housing properties in Tehran, capital of Iran, we investigate the effect of metro station inauguration on prices of proximate properties considering the proximity of other public transportation such as Bus Rapid Transit (BRT) to those Metro stations. In summary, we find that opening of the metro station in Tehran, on average, significantly has increased the price of housing in the regions around them. Studying the impact of all stations after their opening shows a $3.7 \%$ increase in property prices at a radius of 400 meters from the metro station compared with the property at a radius of 400 meters to 3 kilometers. This finding confirms earlier studies that the advantage of metro station due to ease of access to other city regions overcomes the possible disadvantages of crowding and pollution, confirming the results of Chen et al. (1998).

Using diversity of various city regions, we find that the lower the initial quality and volume of public transport near the opened metro station is, the more profound the positive effect on the price of surrounding properties will be. Our study finds the price increase of 2 to $11 \%$ of the nearby properties with less ex ante access to public modes of transportation. However, if these stations open in regions with an extensive public transportation system such as BRT lines, then there will be no significant positive impact on housing prices in those regions or even negative impact.

It is worth noting that it usually takes time for the construction of metro station from the date that the construction is publicized to the actual date of opening. Therefore, in practice, prices can adjust to the news of metro inauguration before the inauguration takes place. It implies that by comparison of prices before and after inauguration, we underestimate the effect of metro stations. Hence we interpret our findings as minimum effect of metro stations on the house prices. Nevertheless, the result of this research shows that metro operation in Tehran generally results in at least a 3.7\% increase in housing prices. Finally, further research is needed to study dynamics of house price adjustment which was beyond scope of this research.

\section{Appendix}

\subsection{Calculate Distance and latitude-longitude}

The geographic coordinate system is a system through which the location of each point on the earth can be determined using several components. In the coordinates, one component represents the vertical location or the height of the desired point, and the second component determines the horizontal location. An ordinary coordinate system has three components, height (elevation), latitude, and longitude. Latitude $(\phi)$ of each point is the northern or southern angle between the equatorial plane and the line passing through the point and the center of the earth. Points with the same latitude constitute the circuits, the circles parallel to the Equator that their radiuses vary from the largest (the Equator) to the smallest (in poles). The longitude $(\lambda)$ of a point represents the eastern or western angle between the meridian on which the point is located and the prime meridian, whose longitude is zero degree. This angle is at most $180^{\circ} \mathrm{E}$ (East) or W (West).

The city of Tehran expands between $51^{\circ} 24^{\prime} E$ and $51^{\circ} 36^{\prime} E$ longitude with an approximate length of $50 \mathrm{~km}$ and between $35^{\circ} 34^{\prime} E$ and $35^{\circ} 50^{\prime} E$ latitude with approximately $30 \mathrm{~km}$ width. The geographic coordinates of each point as degrees, minutes, and seconds can be converted to the decimal degrees by the following formula:

$$
\text { Decimal Degrees }=\text { Degrees }+(\text { Minutes } / 60)+(\text { Seconds } / 3600)
$$

For example:

$$
35^{\circ} 40^{\prime} 20^{\prime \prime}=35+\frac{40}{60}+\frac{20}{3600}=35.672222
$$


To convert decimal degrees to radians it is enough to use the following formula:

$$
\text { Radians }=\text { Decimal Degrees } * \frac{2 \pi}{360}
$$

To calculate the distance between the properties and metro stations using geographic coordinates, we should convert any geographic coordinates in decimal degrees into geographic coordinates in kilometers. The conversion of the decimal point to the kilometer varies depending on the location of that point on the globe. Let $l t_{1} \cdot l g_{1}$ and $l t_{2} \cdot l_{g_{2}}$ be the geographical latitude and longitude in radians of two points 1 and 2, and LT.LG be their absolute differences; then $L T$, the central angle between them, is given by the spherical law of cosines if one of the poles is used as an auxiliary third point on the sphere:

$$
\begin{gathered}
L T=\arccos \left(\sin l t_{1} * \sin l t_{2}+\cos l t_{1} * \cos l t_{2} * \cos (L G)\right) \\
d=r * L T \cdot r=6371 \mathrm{~km}(\text { Radius for Sphere Earth })
\end{gathered}
$$

\subsection{Data Cleaning}

Data, received from the Ministry of Roads and Urban Development, include the total number of monthly transactions throughout the country. As mentioned before, a total of 3,900,000 transactions were conducted all over the country. Since, in this research, housing prices in Tehran must be surveyed, in the first step, only transactions of Tehran are retained that included about 1,350,000 transactions. At the next step, the data on the first six digits of the postal codes, given from the Post Office, was merged with the housing price data to eliminate traded properties whose postal codes were not in the database. About 20,000 transactions were removed at this stage because their postal codes were not accurately recorded. The remaining was arranged according to the type, and only residential properties were considered. At this stage, about 2,000 transactions were eliminated. Reasonable intervals were considered for the parameters the price per square meter, the age of the building, and the surface area of the property, then the data outside that intervals were removed. The transactions in the $0.5 \%$ up and down of the data based on their price per square meter were omitted which about 15,000 transactions were in this range. For the parameter age of the building and area, properties within the 100th percentile based on their age and surface area were removed. In overall, after applying the restrictions and screening the data, the number of transactions left was $1,260,000$ cases.

\subsection{Robustness check - Treatment Group}

To check robustness of the model, we change the value of the boundary from $400 \mathrm{~m}$ to $200,600,800 \mathrm{~m}$ and $1 \mathrm{~km}$, and we also examine the output in these states. According to the results in the Table (7), by enlarging the region around the metro station, the growth rate decreases.

According to the Table (7), if the boundaries under experiment are reduced, the effect of the opening of the metro station on the price of the property in the corresponding region will be more apparent. More precisely, if the range considered being $200 \mathrm{~m}$ or $400 \mathrm{~m}$, the effect of the opening of the metro station on the prices is $3.7 \%$. However, if we increase the radius of the region under study to $1 \mathrm{~km}$, the effect of the opening of the metro station on the prices will nearly disappears. The basic case that is considered in this research is the distance one can ordinarily walk, which here are assumed 400 meters.

\subsection{Robustness check - Control Group}

In the Table (8), we also examine the range under control for other distances. In the basic case, the range under study is $3 \mathrm{~km}$. According to the Table (8) using the control variables of the age of the building, the surface area, the region fixed effect, and the date of the transaction, if we reduce the range of controlled boundary to $2 \mathrm{~km}$, the effect of the opening of the metro station on the property 
Table 7: Regression results in different ranges of treatment group

\begin{tabular}{|c|c|c|c|c|c|}
\hline & $\begin{array}{c}(1) \\
200 \mathrm{~m}\end{array}$ & $\begin{array}{c}(2) \\
400 \mathrm{~m}\end{array}$ & $\begin{array}{c}(3) \\
600 \mathrm{~m}\end{array}$ & $\begin{array}{c}(4) \\
800 \mathrm{~m}\end{array}$ & $\begin{array}{c}(5) \\
1000 \mathrm{~m}\end{array}$ \\
\hline $\mathrm{T}=1^{*} \mathrm{M} 1=1$ & $\begin{array}{c}0.0484^{* * *} \\
(0.0062)\end{array}$ & & & & \\
\hline Age (centuries) & $\begin{array}{c}-2.4984^{* * *} \\
(0.0125)\end{array}$ & $\begin{array}{c}-2.5031^{* * *} \\
(0.0125)\end{array}$ & $\begin{array}{c}-2.5052^{* * *} \\
(0.0125)\end{array}$ & $\begin{array}{c}-2.5119^{* * *} \\
(0.0125)\end{array}$ & $\begin{array}{c}-2.5083^{* * *} \\
(0.0125)\end{array}$ \\
\hline Area $\left(\operatorname{Hectar}^{2}\right)$ & $\begin{array}{c}10.8345^{* * *} \\
(0.3444)\end{array}$ & $\begin{array}{c}10.7197^{* * *} \\
(0.3443)\end{array}$ & $\begin{array}{c}10.6780^{* * *} \\
(0.3442)\end{array}$ & $\begin{array}{c}10.6476^{* * *} \\
(0.3441)\end{array}$ & $\begin{array}{c}10.8049^{* * *} \\
(0.3441)\end{array}$ \\
\hline $\operatorname{Age}^{2}$ (centuries) & $\begin{array}{c}4.1609^{* * *} \\
(0.0352)\end{array}$ & $\begin{array}{c}4.1717^{* * *} \\
(0.0352)\end{array}$ & $\begin{array}{c}4.1743^{\text {*** }} \\
(0.0352)\end{array}$ & $\begin{array}{c}4.1881^{\text {*** }} \\
(0.0351)\end{array}$ & $\begin{array}{c}4.1844^{* * *} \\
(0.0352)\end{array}$ \\
\hline $\operatorname{Area}^{2}\left(\operatorname{Hectar}^{2}\right)$ & $\begin{array}{c}110.7304^{* * *} \\
(12.2888)\end{array}$ & $\begin{array}{c}114.3933^{* * *} \\
(12.2858)\end{array}$ & $\begin{array}{c}116.0682^{* * *} \\
(12.2818)\end{array}$ & $\begin{array}{c}116.9601^{* * *} \\
(12.2776)\end{array}$ & $\begin{array}{c}113.1338^{* * *} \\
(12.2798)\end{array}$ \\
\hline $\mathrm{T}=1^{*} \mathrm{M} 2=1$ & & $\begin{array}{c}0.0371^{* * *} \\
(0.0030)\end{array}$ & & & \\
\hline $\mathrm{T}=1 * \mathrm{M} 3=1$ & & & $\begin{array}{c}0.0271^{\text {**** }} \\
(0.0022)\end{array}$ & & \\
\hline $\mathrm{T}=1^{*} \mathrm{M} 4=1$ & & & & $\begin{array}{c}0.0136^{\text {*** }} \\
(0.0019)\end{array}$ & \\
\hline $\mathrm{T}=1^{*} \mathrm{M} 5=1$ & & & & & $\begin{array}{c}0.0111^{* * *} \\
(0.0019)\end{array}$ \\
\hline Constant & $\begin{array}{c}-0.0388 \\
(0.2510)\end{array}$ & $\begin{array}{c}-0.0441 \\
(0.2509)\end{array}$ & $\begin{array}{c}-0.0575 \\
(0.2509)\end{array}$ & $\begin{array}{c}-0.0693 \\
(0.2508)\end{array}$ & $\begin{array}{l}-0.0659 \\
(0.2508)\end{array}$ \\
\hline $\mathrm{N}$ & 833,281 & 833,281 & 833,281 & 833,281 & 833,281 \\
\hline $\mathrm{R}$-squared & .7522 & .7524 & .7526 & .7527 & .7526 \\
\hline
\end{tabular}

Standard errors in parentheses

${ }^{*} p<0.05,{ }^{* *} p<0.01,{ }^{* * *} p<0.001$

Comments: As shown in the table, the post ${ }^{*}$ treat coefficient is increased by shrinking the range.

price appears more significantly. More specifically, if the range under control is considered up to $2 \mathrm{~km}$, the effect of the metro opening will be $4.1 \%$, while if we increase the range up to $6 \mathrm{~km}$, the impact of the metro opening will be approximately $3 \%$. As said before, the basic case considered in this research is up to $3 \mathrm{~km}$.

\subsection{Robustness check - Stepwise-Linear-Quadratic Model}

Table (9) reports the results of models we consider here. In the primary model, the distance was divided into two categories coded by $0(400 \mathrm{~m}$ to $3 \mathrm{~km}$ ) and 1 (up to $400 \mathrm{~m})$. Here, for robustness check we consider the distance as a linear and a quadratic function, and only transactions within the range of $1 \mathrm{~km}$ of the metro station are considered, the number of transactions is 305,468 in this case. Also, a case 
Table 8: Regression results in different ranges of control group

\begin{tabular}{|c|c|c|c|c|c|}
\hline & $\begin{array}{c}(1) \\
2 \mathrm{~km}\end{array}$ & $\begin{array}{c}(2) \\
3 \mathrm{~km}\end{array}$ & $\begin{array}{c}(3) \\
4 \mathrm{~km}\end{array}$ & $\begin{array}{c}(4) \\
5 \mathrm{~km}\end{array}$ & $\begin{array}{l}(5) \\
6 \mathrm{~km}\end{array}$ \\
\hline $\mathrm{T}=1^{*} \mathrm{M} 1=1$ & $\begin{array}{c}0.0413^{* * *} \\
(0.0030)\end{array}$ & & & & \\
\hline Age (centuries) & $\begin{array}{c}-2.5158^{* * *} \\
(0.0143)\end{array}$ & $\begin{array}{c}-2.5031^{* * *} \\
(0.0125)\end{array}$ & $\begin{array}{c}-2.4259^{* * *} \\
(0.0117)\end{array}$ & $\begin{array}{c}-2.3996^{* * *} \\
(0.0112)\end{array}$ & $\begin{array}{c}-2.3846^{* * *} \\
(0.0108)\end{array}$ \\
\hline Area (Hectares) & $\begin{array}{c}7.7151^{* * * *} \\
(0.3964)\end{array}$ & $\begin{array}{c}10.7196^{* * *} \\
(0.3442)\end{array}$ & $\begin{array}{c}12.3332^{* * * *} \\
(0.3236)\end{array}$ & $\begin{array}{c}12.2424^{* * *} \\
(0.3108)\end{array}$ & $\begin{array}{c}12.4509^{* * *} \\
(0.3007)\end{array}$ \\
\hline $\operatorname{Age}^{2}$ (centuries) & $\begin{array}{c}4.1837^{* * *} \\
(0.0402)\end{array}$ & $\begin{array}{c}4.1717^{* * * *} \\
(0.0352)\end{array}$ & $\begin{array}{c}4.0274^{* * *} \\
(0.0333)\end{array}$ & $\begin{array}{c}4.0404^{* * *} \\
(0.0321)\end{array}$ & $\begin{array}{c}4.0831^{\text {*** }} \\
(0.0312)\end{array}$ \\
\hline Area $^{2}$ (Hectares) & $\begin{array}{c}2.21 \times 10^{2 * * *} \\
\quad(14.2462)\end{array}$ & $\begin{array}{c}11.14 \times 10^{2 * * *} \\
\quad(12.2858)\end{array}$ & $\begin{array}{c}6.84 \times 10^{* * * *} \\
(11.6416)\end{array}$ & $\begin{array}{l}9 \times 10^{* * *} \\
(11.2525)\end{array}$ & $\begin{array}{c}1.028 \times 10^{2 * * *} \\
\quad(10.9528)\end{array}$ \\
\hline $\mathrm{T}=1^{*} \mathrm{M} 2=1$ & & $\begin{array}{c}0.0371^{\text {*** }} \\
(0.0030)\end{array}$ & & & \\
\hline $\mathrm{T}=1^{*} \mathrm{M} 3=1$ & & & $\begin{array}{c}0.0349^{* * *} \\
(0.0030)\end{array}$ & & \\
\hline $\mathrm{T}=1^{*} \mathrm{M} 4=1$ & & & & $\begin{array}{c}0.0342^{* * *} \\
(0.0030)\end{array}$ & \\
\hline $\mathrm{T}=1^{*} \mathrm{M} 5=1$ & & & & & $\begin{array}{c}0.0307^{* * *} \\
(0.0030)\end{array}$ \\
\hline Constant & $\begin{array}{c}-0.0341 \\
(0.2495)\end{array}$ & $\begin{array}{c}-0.0441 \\
(0.2509)\end{array}$ & $\begin{array}{c}-0.1212 \\
(0.2539)\end{array}$ & $\begin{array}{c}-0.1341 \\
(0.2534)\end{array}$ & $\begin{array}{c}-0.1510 \\
(0.2528)\end{array}$ \\
\hline $\mathrm{N}$ & 628,782 & 833,281 & 977,048 & $1,077,506$ & $1,169,264$ \\
\hline R-squared & .7538 & .7524 & .7478 & .7481 & .7478 \\
\hline
\end{tabular}

Standard errors in parentheses

${ }^{*} p<0.05,{ }^{* *} p<0.01,{ }^{* * *} p<0.001$

Comments: As shown in the table, the post ${ }^{*}$ treat coefficient is increased by shrinking the range.

with a stepwise function is considered. In this case, we consider distances to four categories 0 to $150 \mathrm{~m}$, 150 to $400 \mathrm{~m}$ and $400 \mathrm{~m}$ to $1 \mathrm{~km}$ and 1 to $3 \mathrm{~km}$. In the case with stepwise function, the coefficient of the variable of the difference-in-difference in the first category, which includes properties in the range of up to 150 meters from the metro station, is 4.6 percent, which is smaller for the other categories, so that it is negative for the last category ( $400 \mathrm{~m}$ to 1 kilometers). In the linear and quadratic case, the coefficient of the difference-in-difference variable of degree one is $-4.4 \%$, meaning that, up to $1 \mathrm{~km}$, for every 100 meters away from the metro station, $0.44 \%$ of the price of the property is reduced due to the opening of the metro station. As summarized in the Table (9), the coefficient for the term of degree one is equal to $-14 \%$. 
Table 9: Comparison of linear, quadratic and stepwise models

\begin{tabular}{|c|c|c|c|c|}
\hline & $\begin{array}{c}(1) \\
\text { Basic }\end{array}$ & $\begin{array}{c}(2) \\
\text { Stepwise }\end{array}$ & $\begin{array}{c}(3) \\
\text { Linear }\end{array}$ & $\begin{array}{c}\text { (4) } \\
\text { Quadratic }\end{array}$ \\
\hline $\mathrm{T}=1^{*} \mathrm{M}=1$ & $\begin{array}{c}0.0371^{* * *} \\
(0.0030)\end{array}$ & $\begin{array}{c}0.0460^{\text {*** }} \\
(0.0096)\end{array}$ & & \\
\hline $\mathrm{T}=1^{*} \mathrm{M}=2$ & & $\begin{array}{c}0.0362^{\text {*** }} \\
(0.0032)\end{array}$ & & \\
\hline $\mathrm{T}=1^{*} \mathrm{M}=3$ & & $\begin{array}{l}0.0056^{* *} \\
(0.0020)\end{array}$ & & \\
\hline $\mathrm{T}=1^{*} \mathrm{M}$ & & & $\begin{array}{c}-0.0442^{\text {*** }} \\
(0.0055)\end{array}$ & $\begin{array}{c}-0.1434^{* * *} \\
(0.0276)\end{array}$ \\
\hline $\mathrm{T}=1^{*} \mathrm{M} 2$ & & & & $\begin{array}{c}0.0895^{* * *} \\
(0.0230)\end{array}$ \\
\hline Constant & $\begin{array}{l}-0.0441 \\
(0.2509)\end{array}$ & $\begin{array}{l}-0.0667 \\
(0.2508)\end{array}$ & $\begin{array}{c}0.2523^{* * *} \\
(0.0679)\end{array}$ & $\begin{array}{l}0.1934^{* *} \\
(0.0681)\end{array}$ \\
\hline $\mathrm{N}$ & 833,281 & 833,281 & 305,468 & 305,468 \\
\hline $\mathrm{R}$-squared & .7524 & .7527 & .7365 & .7367 \\
\hline
\end{tabular}

Comments: Stepwise, linear and quadratic modes are compared with the initial state. In stepwise mode, the treatment group is divided into 3 groups of less than 150 meters, between 150 and 500 meters and 1000 meters. In linear and quadratic mode, the range is $1 \mathrm{~km}$.

\subsection{Robustness check $-\ln ($ Age $), \ln ($ Area $)$ and categorized age and area}

In Table (10) logarithm of variables $A g e$ and $A r e a$ are used instead of their levels. Moreover, in Table (11) we used 10 decile fixed effects for variables Age and Area. As can be seen, controlled for fixed effects, the effect of metro station inauguration changes slightly with model specification, but this change is negligible regarding its amount. Therefore, we conclude that our results are robust to model specification. 
Table 10: Regression results for $\log$ form of variables

\begin{tabular}{|c|c|c|c|c|c|}
\hline & $\overline{(1)}$ & 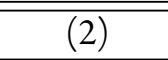 & $\overline{(\overline{(3)}}$ & $\overline{(4)}$ & $\overline{\overline{(5)}}$ \\
\hline $\mathrm{T}=1$ & $\begin{array}{c}0.5941^{* * *} \\
(0.0015)\end{array}$ & $\begin{array}{c}0.6266^{* * *} \\
(0.0014)\end{array}$ & $\begin{array}{c}0.0505^{* * *} \\
(0.0014)\end{array}$ & $\begin{array}{c}-0.0194^{* * *} \\
(0.0013)\end{array}$ & $\begin{array}{c}-0.0265^{* * *} \\
(0.0016)\end{array}$ \\
\hline$M=1$ & $\begin{array}{c}-0.0457^{* * *} \\
(0.0037)\end{array}$ & $\begin{array}{c}0.0513^{\text {*** }} \\
(0.0032)\end{array}$ & $\begin{array}{c}-0.0413^{* * *} \\
(0.0027)\end{array}$ & $\begin{array}{c}0.0211^{\text {*** }} \\
(0.0022)\end{array}$ & $\begin{array}{c}0.0127^{* * *} \\
(0.0022)\end{array}$ \\
\hline $\mathrm{T}=1^{*} \mathrm{M}=1$ & $\begin{array}{l}0.0105^{*} \\
(0.0053)\end{array}$ & $\begin{array}{c}0.0157^{* * *} \\
(0.0045)\end{array}$ & $\begin{array}{l}-0.0063 \\
(0.0039)\end{array}$ & $\begin{array}{c}0.0222^{* * *} \\
(0.0031)\end{array}$ & $\begin{array}{c}0.0371^{* * *} \\
(0.0032)\end{array}$ \\
\hline $\ln$ Age & & $\begin{array}{c}-0.1259^{* * *} \\
(0.0006)\end{array}$ & $\begin{array}{c}-0.0785^{* * *} \\
(0.0005)\end{array}$ & $\begin{array}{c}-0.1069^{* * *} \\
(0.0004)\end{array}$ & $\begin{array}{c}-0.1049^{* * *} \\
(0.0005)\end{array}$ \\
\hline $\ln$ Area & & $\begin{array}{c}0.0883^{* * *} \\
(0.0019)\end{array}$ & $\begin{array}{c}0.5667^{* * *} \\
(0.0013)\end{array}$ & $\begin{array}{c}0.1081^{* * *} \\
(0.0013)\end{array}$ & $\begin{array}{c}0.1076^{* * *} \\
(0.0013)\end{array}$ \\
\hline Constant & $\begin{array}{c}0.8337^{* * *} \\
(0.0012)\end{array}$ & $\begin{array}{c}0.3309^{* * *} \\
(0.0119)\end{array}$ & $\begin{array}{c}-2.0560^{* * *} \\
(0.0507)\end{array}$ & $\begin{array}{c}-0.2625^{* * *} \\
(0.0408)\end{array}$ & $\begin{array}{c}-0.4028 \\
(0.2553)\end{array}$ \\
\hline Region & No & Yes & No & Yes & Yes \\
\hline Quarter & No & No & Yes & Yes & Yes \\
\hline Region*Quarter & No & No & No & No & Yes \\
\hline Frame & No & No & No & No & Yes \\
\hline $\mathrm{N}$ & 833,282 & 759,057 & 759,057 & 759,057 & 759,056 \\
\hline R-squared & .1683 & .4435 & .5708 & .7296 & .736 \\
\hline
\end{tabular}

Standard errors in parentheses

${ }^{*} p<0.05,{ }^{* *} p<0.01,{ }^{* * *} p<0.001$

$\ln$ Area and $\ln A g e$ are exerted instead of Area and Age. 
Table 11: Regression results for categorized form of variables

\begin{tabular}{lccccc}
\hline \hline & $(1)$ & $(2)$ & $(3)$ & $(4)$ & $(5)$ \\
\hline $\mathrm{T}=1$ & $0.5941^{* * *}$ & $0.5921^{* * *}$ & $0.0522^{* * *}$ & $-0.0198^{* * *}$ & $-0.0244^{* * *}$ \\
& $(0.0015)$ & $(0.0014)$ & $(0.0013)$ & $(0.0012)$ & $(0.0015)$ \\
$\mathrm{M}=1$ & $-0.0457^{* * *}$ & $0.0504^{* * *}$ & $-0.0419^{* * *}$ & $0.0227^{* * *}$ & $0.0141^{* * *}$ \\
& $(0.0037)$ & $(0.0030)$ & $(0.0026)$ & $(0.0021)$ & $(0.0021)$ \\
& & & & & \\
$\mathrm{T}=1^{*} \mathrm{M}=1$ & $0.0105^{*}$ & $0.0210^{* * *}$ & -0.0051 & $0.0238^{* * *}$ & $0.0380^{* * *}$ \\
& $(0.0053)$ & $(0.0042)$ & $(0.0037)$ & $(0.0029)$ & $(0.0030)$ \\
& & & & & \\
\hline Age Deciles FE & No & Yes & Yes & Yes & Yes \\
Area Deciles FE & No & Yes & Yes & Yes & Yes \\
\hline Constant & $0.8337^{* * *}$ & $0.8589^{* * *}$ & $0.1502^{* *}$ & $0.1756^{* * *}$ & 0.0386 \\
& $(0.0012)$ & $(0.0086)$ & $(0.0503)$ & $(0.0398)$ & $(0.2510)$ \\
Region & & & & & \\
Quarter & No & Yes & No & Yes & Yes \\
Region*Quarter & No & No & Yes & Yes & Yes \\
Frame & No & No & No & No & Yes \\
\hline $\mathrm{N}$ & 833,282 & 833,282 & 833,282 & 833,282 & 833,281 \\
R-squared & .1683 & .4667 & .5759 & .7444 & .7504 \\
\hline \hline
\end{tabular}

Standard errors in parentheses

${ }^{*} p<0.05,{ }^{* *} p<0.01,{ }^{* * *} p<0.001$

Values for Age and Area are categorized in 10 deciles. First column report regression results for the whole sample without any control and any fixed effect. In columns 2-5, deciles of age and area are-fixed effects are used to control any nonlinear effect of these variables. 


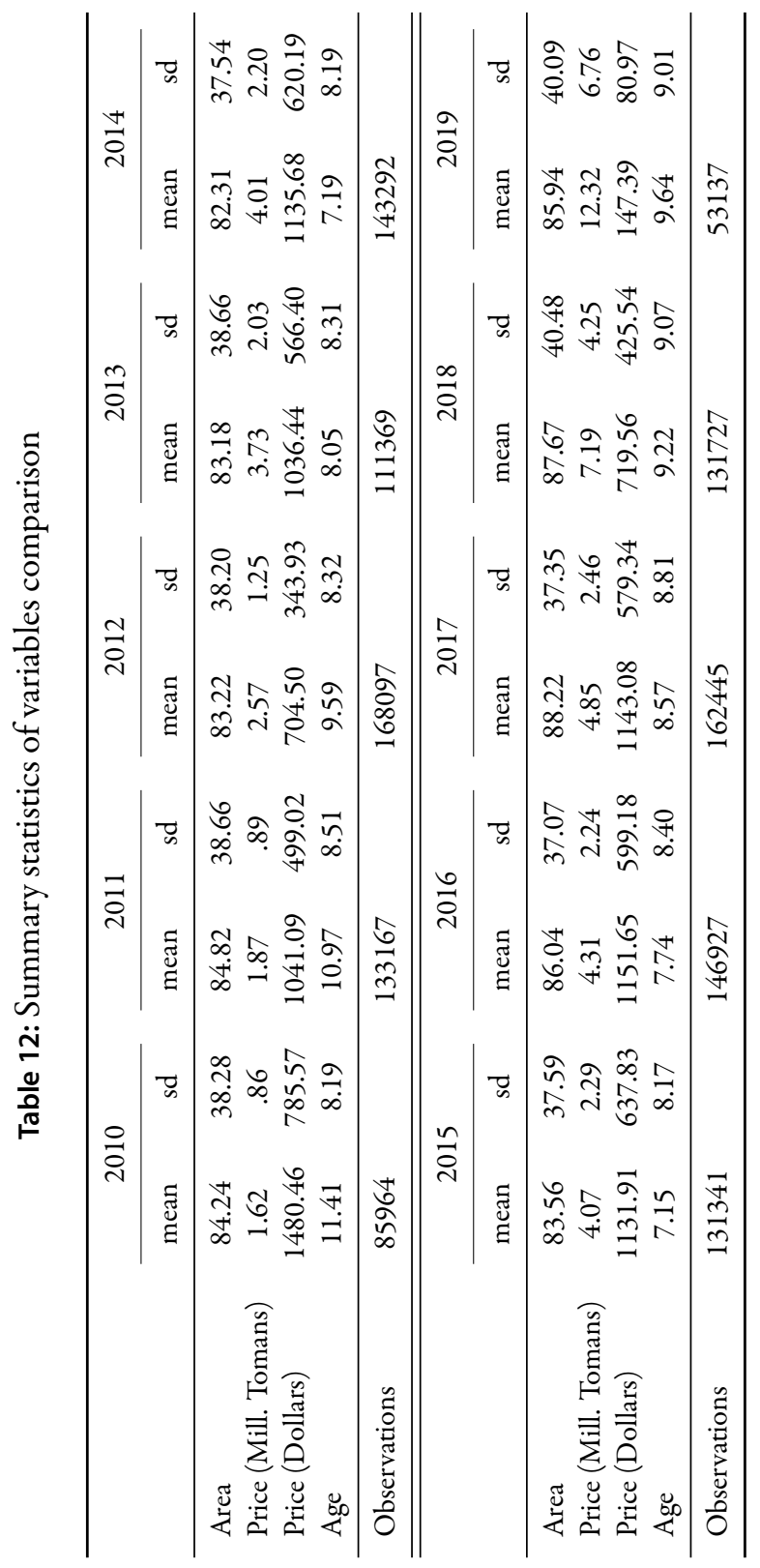




\section{References}

Badoe, D. A. and E. J. Miller. 2000. Transportation-land-use interaction: Empirical findings in North America, and their implications for modeling. Transportation Research Part D: Transport and Environment, 5(4):235-263.

Bajic, V. 1983. The effects of a new subway line on housing prices in metropolitan Toronto. Urban Studies, 20(2):147-158.

Baker, C. 1983. Tracking Washington's Metro. American Demographics, 5(11):30-35.

Billings, S. B. 2011. Estimating the value of a new transit option. Regional Science and Urban Economics, 41(6):525-536.

Bohman, H. and D. Nilsson. 2016. The impact of regional commuter trains on property values: Price segments and income. Journal of Transport Geography, 56:102-109.

Bowes, D. R. and K. R. Ihlanfeldt. 2001. Identifying the impacts of rail transit stations on residential property values. Journal of Urban Economics, 50(1):1-25.

Bryan, G., E. Glaeser, and N. Tsivanidis. 2019. Cities in the developing world. Technical report, National Bureau of Economic Research.

Chen, H., A. Rufolo, and K. J. Dueker. 1998. Measuring the impact of light rail systems on singlefamily home values: A hedonic approach with Geographic Information System application. Transportation Research Record, 1617(1):38-43.

Chica-Olmo, J., R. Cano-Guervos, and I. Tamaris-Turizo. 2019. Determination of buffer zone for negative externalities: Effect on housing prices. The Geographical Journal, 185(2):222-236.

Coffman, C. and M. E. Gregson. 1998. Railroad development and land value. The Journal of Real Estate Finance and Economics, 16(2):191-204.

Debrezion, G., E. Pels, and P. Rietveld. 2011. The impact of rail transport on real estate prices: An empirical analysis of the Dutch housing market. Urban Studies, 48(5):997-1015.

Diao, M. 2015. Selectivity, spatial autocorrelation and the valuation of transit accessibility. Urban Studies, 52(1):159-177.

Diao, M., D. Leonard, and T. F. Sing. 2017. Spatial-difference-in-differences models for impact of new mass rapid transit line on private housing values. Regional Science and Urban Economics, 67:64-77.

Diao, M., Y. Qin, and T. F. Sing. 2016. Negative externalities of rail noise and housing values: Evidence from the cessation of railway operations in Singapore. Real Estate Economics, 44(4):878-917.

Forouhar, A. and M. Hasankhani. 2018. The effect of Tehran metro rail system on residential property values: A comparative analysis between high-income and low-income neighbourhoods. Urban Studies, 55(16):3503-3524.

Forrest, D., J. Glen, and R. Ward. 1996. The impact of a light rail system on the structure of house prices: A hedonic longitudinal study. Journal of Transport Economics and Policy, pp. 15-29.

Giuliano, G. 2004. Land use impacts of transportation investments. The Geography of Urban Transportation, 3:237-273.

Hess, D. B. and T. M. Almeida. 2007. Impact of proximity to light rail rapid transit on station-area property values in Buffalo, New York. Urban Studies, 44(5-6):1041-1068.

Hu, L., S. He, Z. Han, H. Xiao, S. Su, M. Weng, and Z. Cai. 2019. Monitoring housing rental prices based on social media: An integrated approach of machine-learning algorithms and hedonic modeling to inform equitable housing policies. Land Use Policy, 82:657-673.

McMillen, D. P. and J. McDonald. 2004. Reaction of house prices to a new rapid transit line: Chicago's Midway line, 1983-1999. Real Estate Economics, 32(3):463-486.

Mohammad, S. I., D. J. Graham, and P. C. Melo. 2015. The effect of the Dubai Metro on the value of residential and commercial properties. Journal of Transport and Land Use, 10(1).

Murat Celik, H. and U. Yankaya. 2006. The impact of rail transit investment on the residential property values in developing countries: The case of Izmir subway, Turkey. Property Management, $24(4): 369-382$. 
Pope, D. G. and J. C. Pope. 2015. When Walmart comes to town: Always low housing prices? Always? Journal of Urban Economics, 87:1-13.

Railway-Technology.com. 2014. Tehran Metro, Iran. Technical report, Archived from the original on 2014-07-01. Retrieved 2014-06-29.

Ransom, M. R. 2018. The effect of light rail transit service on nearby property values. Journal of Transport and Land Use, 11.

Ryan, S. 1999. Property values and transportation facilities: Finding the transportation-land use connection. Journal of Planning Literature, 13.

Stewart, O. T., A. V. Moudon, and B. E. Saelens. 2017. The causal effect of Bus Rapid Transit on changes in transit ridership. Journal of Public Transportation, 20(1):91.

Sun, H., Y. Wang, and Q. Li. 2016. The impact of subway lines on residential property values in Tianjin: An empirical study based on hedonic pricing model. Discrete Dynamics in Nature and Society, 2016.

Vessali, K. V. 1996. Land use impacts of rapid transit: A review of the empirical literature. Berkeley Planning Journal, 11(1).

Wu, W., G. Dong, and B. Wang. 2015. Does planning matter? Effects on land markets. The Journal of Real Estate Finance and Economics, 50(2):242-269.

Yang, J. Z., Linchuan and O. F. Shyr. 2019. Does bus accessibility affect property prices? Cities, 84. 